\title{
Atendimento odontológico domiciliar aos idosos: uma necessidade na prática multidisciplinar em saúde: revisão de literatura
}

\author{
Home dental care for the elderly: a need in health multidisciplinary practice: literature review
}

\section{Resumo}

O atendimento odontológico domiciliar direcionado aos idosos semi e dependentes é conjunto de ações preventivas e de mínima intervenção que visam promover a saúde bucal e orientar familiares e cuidadores. É considerada uma estratégia educativa e assistencial de saúde cuja finalidade é intervir, de maneira multidisciplinar, no processo saúde-doença de idosos vulneráveis. Este estudo tem como objetivo abordar a prática odontológica domiciliar, enfatizando as principais alterações sistêmicas e possíveis repercussões na cavidade bucal, a necessidade de participação efetiva do cirurgiãodentista e orientações de promoção de saúde bucal que possam auxiliar nas condutas dos familiares, cuidadores e profissionais envolvidos com esse tipo de atendimento. Foram realizadas busca e análise de artigos científicos e bases de dados bibliográficos sobre a prática odontológica domiciliar em idosos. Na estratégia de busca foram empregados os termos: assistência domiciliar, odontogeriatria, odontologia domiciliar, idoso fragilizado e saúde bucal. Adotaram-se como critérios de inclusão: artigos publicados em português; artigos indexados nas bases de dados LILACS e SciELO; artigos publicados no período de 2000 a 2011 e legislação federal sobre o assunto, totalizando 36 referências. Concluiu-se que existe grande necessidade dessa atividade odontológica em domicílio a ser executada de maneira capacitada por odontogeriatras com formação gerontológica que possam contribuir na humanização do atendimento e promoção do bem-estar e qualidade de vida desses idosos.

\section{Abstract}

Home dental service for semi and dependent elderly is a set of preventive actions and minimal intervention aimed at establishing the promotion of oral health and guidance to families and caregivers. It is considered an educational strategy and health care whose purpose is to provide multidisciplinary intervention in the health-disease process of vulnerable elderly. This report aimed to approach home dental practice, emphasizing
Danielle Aline Rocha' Alexandre Franco Miranda'
Palavras-chave: Assistência Domiciliar. Odontologia Geriátrica. Saúde Bucal.

Curso de Odontologia, Campus I. Universidade Católica de Brasília. Taguatinga, DF, Brasil. 
the main systemic changes and possible repercussions in the oral cavity, the need for effective participation of surgeon-dentist and guidelines to promote oral health that may help family members, caregivers and professionals involved with this type of care. Scientific articles and bibliographic databases on the dental practice-based study in the elderly were searched and analyzed. Search strategy terms were: home care, geriatric dentistry, dental home care, frail elderly, oral health. Inclusion criteria were: published articles in Portuguese; articles indexed in the databases LILACS and SciELO; articles published from 2000 to 2011 and federal laws on the subject, totaling 36 references. It was concluded that there is a great need of home dental activity to be performed by skilled geriatric dentists with geriatric training that can contribute in humanizing care and promote well-being and quality of life for elderly people.
Key words: Home Nursing. Geriatric Dentistry. Oral Health.

\section{INTRODUÇÃO}

A expectativa e qualidade de vida aumentadas da população brasileira contribuem para o surgimento de doenças específicas da velhice, principalmente relacionadas à interação sistêmica com o aparelho estomatognático, havendo a necessidade de incentivos em saúde por meio de programas governamentais de acesso ao tratamento odontológico para esse grupo populacional. ${ }^{1-3}$

De acordo com a Política Nacional de Saúde do Idoso, o atendimento na atenção básica domiciliar tem como objetivo promover a integração com os demais níveis de atenção e garantir a integralidade por meio da aplicação de modalidades que atendam às necessidades dessa população, a partirde condutas multidisciplinares, sempre que possível. ${ }^{1,4}$

O direito ao atendimento domiciliar, previsto na Constituição Brasileira, enfatiza que a família, a sociedade e o Estado têm o dever de amparar as pessoas idosas, assegurando a participação na comunidade, defendendo a dignidade, bem-estar e garantindo-lhes o direito à vida. ${ }^{5,6}$ Esse tipo de atendimento constitui um conjunto de ações direcionadas ao atendimento individual, familiar e da comunidade; sendo considerada uma estratégia educativa, assistencial e principalmente de saúde, com a finalidade de subsidiar a intervenção no processo saúde-doença de indivíduos vulneráveis ou no planejamento de ações coletivas.?
Os atendimentos domiciliares são caracterizados pela ida do profissional da saúde na residência dos pacientes, bem como no ambiente em que vivem, sendo considerado um método para o estabelecimento de um plano assistencial voltado à prevenção, recuperação (reabilitação) e manutenção da saúde, principalmente de idosos semi e dependentes. ${ }^{7,8}$ Essa prática contribui na manutenção do estímulo do idoso à vida, além da efetiva participação familiar nas condutas multidisciplinares e de orientações aos idosos e cuidadores. ${ }^{4,6}$

A partir desse contexto dedicado à promoção de saúde, surge a necessidade de uma efetiva ação clínica e educacional a ser realizada pelos profissionais da Odontologia capacitados na prática domiciliar. ${ }^{9,10}$

A odontologia domiciliar pode ser considerada como mais uma área de atuação odontológica a ser realizada pelo cirurgião-dentista, com ênfase multidisciplinar, em que se avalia o paciente como um todo e contribui na promoção de uma qualidade de vida saudável e funcional, quando possível, para essas pessoas. ${ }^{2,711}$ Poucos são os relatos na literatura a respeito dessa específica prática odontológica, talvez pela falta de capacitação profissional em atuar de maneira multidisciplinar e de adaptação profissional, ou o desconhecimento por parte dos próprios pacientes, familiares e profissionais envolvidos a respeito da existência desses serviços. ${ }^{8,12-14}$ 
Diante dessa emergente oportunidade de prática odontológica geriátrica, pouco explorada pelo cirurgião-dentista, falta de estudos específicos e de relatos clínicos multidisciplinares, o presente estudo tem como objetivo, por meio de uma revisão de literatura, abordar os principais aspectos relacionados ao atendimento odontológico domiciliar aos idosos semi e dependentes.

\section{METODOLOGIA}

Foi realizado um levantamento de estudos publicados sobre a prática odontológica domiciliar em idosos. Realizou-se levantamento bibliográfico por meio de estratégia de busca com base nos termos: assistência domiciliar, odontogeriatria, odontologia domiciliar, idoso fragilizado, saúde bucal.

Os resumos dos artigos recuperados foram analisados para verificar o atendimento aos critérios de inclusão e exclusão. Adotaram-se como critérios de inclusão: artigos publicados em português; artigos indexados nas bases de dados LILACS e SciELO; artigos publicados no período de 2000 a 2011 e legislação federal sobre o tema. Utilizaram-se como critérios de exclusão: estudos sem informações sobre a amostragem e análise efetuada; teses e dissertações. Considerando as bases científicas analisadas, 36 referências relacionadas ao tema da odontologia domiciliar atenderam aos critérios de seleção estabelecidos.

\section{REVISÃO DE LITERATURA E DISCUSSÃO}

\section{0 cuidado do idoso}

O cuidar da pessoa idosa é formado por uma tríade: idoso e família, grupo de apoio à comunidade e equipe de atenção em saúde, os quais devem estar sincronizados para se obter um resultado satisfatório na atenção ao idoso. ${ }^{4,13} \mathrm{~A}$ população idosa que necessita de cuidados especiais pode ser dividida de acordo com seu estado físico, mental e social, necessitando de diferentes tipos de tratamento, enfatizam Souza \& Caldas.

A necessidade do atendimento odontológico domiciliar tem mostrado muita efetividade, pois devolve ao idoso um bem-estar, além de confiança na qualidade do trabalho exercido pelo profissional qualificado para tal, que procura estabelecer uma melhoria da saúde do paciente. ${ }^{13-15}$ Essas intervenções proporcionam maior humanização do atendimento, pois, na maioria das vezes, o idoso está impossibilitado de se deslocar para o consultório, por motivos como fraqueza e dependência, fazendo com que o cirurgião-dentista se desloque ao encontro do paciente. ${ }^{16,17}$

De acordo com Floriani \& Schramm, ${ }^{2}$ essa população era tratada em ambientes hospitalares e, atualmente, é transferida o mais rápido possível para o domicílio em que se realiza uma minuciosa abordagem multidisciplinar e avaliação do riscobenefício previamente ao tratamento e cuidados propostos.

\section{Idosos dependentes e semidependentes}

Os idosos semi e dependentes são pessoas que dependem da ajuda de outros para a realização das atividades diárias como alimentação, tomar banho e manutenção de uma satisfatória higienização bucal. ${ }^{14,16}$ Geralmente, esses idosos são acometidos por doenças de ordens diversas que necessitam diretamente do suporte do cuidador e familiar, devendo o plano de tratamento odontológico ser apresentado de forma multidisciplinar de maneira a preservar a saúde bucal sem prejudicar a saúde sistêmica desses indivíduos. ${ }^{11,12}$

\footnotetext{
Segundo Souza \& Caldas $^{9}$ e Silveira e colaboradores, ${ }^{16}$ os cuidadores devem estar preparados para condições de manejo psicológico em que o não sofrimento, carinho, cuidado, confiança e aproximação podem elevar a autoestima do idoso dependente, contribuindo para a superação de futuras dificuldades e aceitações negativas. ${ }^{17,18}$
} 


\section{Saúde sistêmica e bucal do idoso}

Os idosos muitas vezes são comprometidos por diversas enfermidades como cardiopatias, pneumonia, endocardite bacteriana, diabetes, doença de Alzheimer e outras moléstias relacionadas ao envelhecimento que acabam refletindo diretamente no bem-estar dessa população. Marca-se o surgimento de novos e melhoramentos dos recursos utilizados em saúde para o estabelecimento de uma maior expectativa de vida com qualidade para os idosos. ${ }^{8,14,19-21}$

\section{Hipertensão arterial}

A pressão arterial alta (hipertensão) é um distúrbio assintomático e é uma das principais causas de morte da população adulta e idosa brasileira. A hipertensão é a elevação anormal da pressão nas artérias aumentando assim os riscos de distúrbios do sistema orgânico., ${ }^{2,20}$

Conforme orientam Santos e colaboradores, ${ }^{20}$ os pacientes hipertensos controlados são considerados de risco aceitável no tratamento odontológico a partir de um atendimento sob monitorização da pressão arterial durante toda a consulta, em domicílio.

Deve ser evitada a administração de altas concentrações de vasoconstritores, se houver a necessidade de anestesias odontológicas, pois aumentam o risco de desenvolvimento de resposta adversa. São recomendados anestésicos locais com concentrações de adrenalina de 1:200.000 ou 1:100.000; mepivacaína 3\% ou prilocaína 4\%. As concentrações não são contraindicadas, porém não devem ultrapassar o limite de dois tubetes, no máximo, indicado para cada paciente. ${ }^{10,18}$

\section{Pneumonia aspirativa}

Apresenta elevada frequência em pacientes idosos semi e dependentes, devido à aspiração de conteúdos contaminantes presentes na cavidade bucal, como biofilme e saburra lingual, em direção à orofaringe. Por isso, é de extrema importância a manutenção da saúde bucal desses idosos, a fim de minimizar ou eliminar esses reservatórios microbianos presentes na cavidade bucal e relacionados com os agentes causais da pneumonia. ${ }^{19,22}$

Segundo Doro e colaboradores, ${ }^{23}$ a saúde bucal insatisfatória é um grande fator de risco para contaminações, pois a aspiração de conteúdo bacteriana presente na cavidade bucal, associados à dificuldade de deglutição presente nesses idosos, promove a contaminação do trato respiratório inferior.

Em idosos dependentes usuários de próteses, essa condição sistêmica é bastante comum, pois por não conseguirem realizar uma correta higienização das mesmas, acabam contribuindo para a maior formação do biofilme nas próteses que acaba sendo aspirado., ${ }^{3,24}$ Por isso, a necessidade de políticas preventivas e de orientações em saúde e higienização bucal, lingual e das próteses para os familiares e cuidadores desses idosos. ${ }^{19}$

\section{Endocardite bacteriana}

A endocardite bacteriana é uma infecção que ocorre nas válvulas cardíacas ou tecidos endoteliais do coração. É uma doença grave que apresenta grande risco a vida e seu desenvolvimento está relacionado com bacteremias, podendo estar presente em idosos mais vulneráveis e de relação direta com focos infecciosos presentes na cavidade bucal. ${ }^{20,25}$

O cirurgião-dentista deve atentar-se em todos os procedimentos invasivos que serão realizados nesses pacientes e em âmbito domiciliar. Deve executá-los de maneira segura para que se evite o desencadeamento dessa doença, principalmente em idosos já submetidos a intervenções cirúrgicas cardíacas. ${ }^{17,26}$

A utilização de antibióticos, profilaxia antibiótica, antes dos procedimentos odontológicos, a partir de um planejamento e 
execução multidisciplinar, principalmente com o médico responsável do paciente, é uma medida segura e necessária a ser utilizada previamente a procedimentos odontológicos em pacientes com alto risco, evitando-se assim a bacteremia transitória. ${ }^{25,27}$

\section{Diabetes Mellitus}

A diabetes mellitus é um distúrbio no metabolismo da glicose orgânica e afeta milhões de indivíduos e é uma doença sistêmica muito presente em pacientes idosos. ${ }^{28}$ Os indivíduos idosos diabéticos têm elevado risco de manifestarem a doença periodontal, perda de tecido de suporte dentário, caracterizada por ser de progressão rápida e agressiva. ${ }^{28-30}$

Outra condição clínica apresentada é a presença de xerostomia, ardor na língua, eritema e alteração no paladar, sendo necessárias ações em saúde bucal que minimizem esses efeitos como saliva artificial, e utilização de antissépticos bucais de maneira correta. ${ }^{29}$

Orientações em saúde bucal aos cuidadores e visitas profissionais do cirurgião-dentista ao idoso frágil em domicílio podem favorecer ao nãoprogresso dessas condições insatisfatórias, além de contribuir na possível eliminação e controle desses focos inflamatórios, infecciosos e de dor presentes na cavidade bucal desses idosos. ${ }^{8,31}$

\section{Alzheimer}

A doença de Alzheimer afeta a memória, o aprendizado, a estabilidade emocional e a capacidade de comunicação. Esses pacientes geralmente se tornam cada vez mais incapacitados de desenvolver certas atividades, como por exemplo, cuidados pessoais básicos (tomar banho e higienizar os dentes) com a evolução da doença, necessitando de um suporte domiciliar., ${ }^{4}$

Nas fases mais avançadas da doença, de acordo com Miranda e colaboradores, ${ }^{19}$ perdem a coordenação motora e cognitiva, para a realização de uma boa higienização, contribuindo para o surgimento de doenças periodontais, cárie e lesões de mucosa devido ao uso indevido de próteses, o que determina que o cirurgiãodentista, profissional da saúde mais capacitado na resolução desses problemas, possa ajudar nas atividades em saúde de caráter mais preventivo.

A qualidade de vida tem sido motivo de preocupação constante do ser humano, sendo um compromisso pessoal em busca contínua de uma vida saudável. Em termos de utilização dos serviços de saúde, o profissional da saúde deve trabalhar juntamente com a equipe médica responsável pelo paciente; além de proporcionar serviços que visem mais a saúde e melhora na qualidade de vida do que a melhora da doença, como a prática odontológica capacitada em domicílio. ${ }^{29,32}$

\section{Saúde bucal}

Com a idade, percebemos que a cavidade bucal apresenta mudanças recorrentes do envelhecimento, que podem estar relacionadas com o físico e psicológico do idoso. Ocorrem mudanças no aparelho estomatognático como: mucosas mais frágeis e sensíveis, gengivas retraídas, coloração escurecida dos dentes, perda de vários elementos dentários (edentulismo) por diversos motivos, entre eles os problemas periodontais consequentes de perda de estruturas ósseas; além de cáries e diminuição do fluxo salivar (xerostomia) devido, principalmente, ao uso constante de medicamentos. ${ }^{7,19}$

O edentulismo ainda é uma condição odontológica presente nos idosos, determinada, principalmente, pela falta de políticas preventivas no passado, juntamente com a perda óssea decorrente de problemas periodontais e próteses dentárias que contribuem para essa remodelação e reabsorção óssea. ${ }^{3,17}$ Outra condição que pode estar presente na cavidade bucal dos idosos é a presença da saburra lingual, em que a mesma fica esbranquiçada, que pode servir como possível nicho bateriano e proporcionar o mal hálito aos idosos. ${ }^{9,12}$ 


\section{Prática odontológica domiciliar}

$\mathrm{O}$ atendimento domiciliar surge como uma das alternativas para melhorar a utilização dos recursos em saúde e vem se tornando uma tendência mundial, a que objetiva a promoção e manutenção da doença ou melhorar o nível de independência, contribuindo na diminuição dos efeitos da incapacidade ou da atividade da doença. ${ }^{18,33}$

$\mathrm{O}$ atendimento odontológico domiciliar proporciona ao paciente maior conforto psicológico e de confiança profissional, e muitos acreditam que torna o tratamento mais humanizado, visando o melhor caminho para o restabelecimento, a priori, funcional. ${ }^{30}$

No tratamento em domicílio, o trabalho em equipe deve buscar a terapêutica curativa (tratar o paciente até promover a cura), a paliativa (trata e cuida visando oferecer-lhe melhor qualidade de vida) e a assistência preventiva, a ideal (busca evitar o agravamento da doença), adaptando a cada caso. ${ }^{14,33}$

De acordo com Miranda \& Montenegro, ${ }^{12}$ o cirurgião-dentista deve estar familiarizado e preparado com toda essa situação em que o paciente se encontra, pois uma percepção dos sinais e sintomas de doenças na cavidade bucal, devem ser decifrados pelo profissional odontólogo, a fim de uma execução clínica competente e manos traumática para o paciente. $\mathrm{Na}$ avaliação da terapia odontológica para o idoso, deve-se levar em consideração não só os fatores bucais, mas principalmente os fatores sistêmicos que afetam o mesmo, enfatizam Arcuri e colaboradores. ${ }^{34}$

É de suma importância que odontólogo tenha uma postura ética e discreta diante desse tipo de atendimento sempre acompanhado por um responsável, cuidador e familiar, além da assinatura do Termo de Consentimento Livre e Esclarecido pelo responsável legal..$^{18,35}$

Segundo Brondani, ${ }^{31}$ o cirurgião-dentista deve atentar para o tempo de duração das sessões de atendimento em odontogeriatria, que devem ser rápidas, evitando o desconforto e inquietação do paciente. O tipo de anestésico e a prescrição medicamentosa devem ser bem observados, pois os pacientes apresentam doenças e manifestações diferentes, devendo então, cada medicamento ser prescritos de forma individual, não existindo regras específicas. ${ }^{31,34}$

As dificuldades na aquisição de materiais e equipamentos, bem como as adaptações do ambiente aparecem em diversos casos. É necessária a realização de métodos adaptativos e individualizados, a fim de contribuírem ao acesso à cavidade bucal do paciente de maneira confortável. Os cuidadores, porém, relatam ter muita dificuldade e insegurança, necessitando de mais instruções quanto ao cuidado do idoso no domicílio, principalmente relacionado a instruções de higiene bucal. ${ }^{11,12,21}$

Medidas preventivas e orientações em saúde bucal para o idoso em domićlio

Medidas preventivas e de promoção de saúde bucal devem ser continuamente enfatizadas pelo cirurgião-dentista para a população idosa, em geral. Em domicílio, o enfoque maior deve ser dado aos cuidadores e familiares, geralmente, os principais responsáveis pela execução das medidas de higienização bucal de idosos semi e dependentes. ${ }^{8,12,36}$

Os dentes, implantes e cavidade bucal deve ser higienizada no mínimo três vezes ao dia a partir de corretas orientações, independentemente da marca do produto, sob constante sucção, no caso dos pacientes que não conseguem cuspir. A escova dentária ideal deve ter a haste longa, cabeça pequena e cerdas macias; a quantidade de pasta fluoretada colocada deve ser compatível com o tamanho de uma ervilha; o fio dental ou fita dental deve ser utilizado de forma correta entre os dentes; e o limpador de língua deve ser utilizado para a higienização da mesma, sempre no sentido póstero-anterior. ${ }^{7,31}$

A utilização constante de enxaguantes ou antissépticos bucais não devem ser uma constante 
em pacientes idosos em domicílio, nem de uso rotineiro, pois são coadjuvantes à ação mecânica (escova associada a pasta) que jamais poderá ser substituída por tais soluções. ${ }^{9,12}$

As próteses, também, devem ser higienizadas e retiradas todos os dias, principalmente antes do paciente idoso ir dormir, pois promove um descanso da mucosa bucal e se evita a ocorrência de futuros acidentes. Devem ser higienizadas com sabão neutro, colocadas em um recipiente com água e uma colher de sopa de bicarbonato de sódio; pela manhã deve ser retirada e higienizada com auxílio de escova e água corrente. É importante mencionar que a pasta dentária não tem a função de higienização das próteses. ${ }^{36}$

Segundo Reis \& Marcelo, ${ }^{32}$ é de extrema importância a higienização dos dentes remanescentes e implantes dentários, no caso de usuários de próteses parciais, da mesma maneira como se houvesse todos os dentes presentes na cavidade bucal. A atenção em saúde bucal deve ser uma constante no idoso, independentemente do nível de evolução da doença sistêmica, pois nas fases mais avançadas, as dificuldades ao tratamento odontológico são maiores. ${ }^{20}$

Com o correto diagnóstico e planejamento clínico, o tratamento odontológico se torna mais eficiente e positivo no âmbito domiciliar, pois o idoso se sente mais seguro e participativo nas condutas clínicas em saúde bucal de maneira multidisciplinar. ${ }^{12,34}$

A prevenção é a base de qualquer tratamento, e nos casos de atendimentos domiciliares, a utilização de recursos facilitadores, como abridores de bocas confeccionados, podem favorecer a realização de uma eficiente higienização bucal. ${ }^{1,3}$

Inserção do cirurgião-dentista no

contexto domiciliar (home care)

A prática odontológica domiciliar não é mencionada especificamente no código de ética odontológico, talvez pela falta de conhecimento e preparo profissional. Mas todas as condutas éticas e profissionais devem ser respeitadas nos atendimentos odontológicos domiciliares realizados pelos dentistas, pois estão sujeitos a infrações éticas. ${ }^{35}$

O cirurgião-dentista e sua equipe buscam apoio nas famílias de forma que evitem mais complicações e aumentem as sequelas já instaladas; trabalham em favor da diminuição da ansiedade, respeitando as crenças, valores e as práticas que os cuidadores e idosos já desenvolviam, de forma a integrar o cuidado cultural e o profissional, reforçando o espaço de cuidado da família. ${ }^{13,14,18}$

De acordo com Almeida \& Ferreira ${ }^{15}$ e Silveira e colaboradore ${ }^{16} \mathrm{O}$ atendimento ideal busca que o paciente idoso se sinta bem e confiante no cirurgião dentista e equipe. Buscando acima de tudo, não causar danos e, sim beneficiar o paciente em sua qualidade de vida.

A comunicação com o paciente é um fator considerável no tratamento, onde deve haver o contato físico, expressão facial, fala e outros meios que auxiliem diretamente nas condutas clínicas em saúde bucal a serem planejadas e realizadas. ${ }^{30}$

É importante ressaltar a necessidade de preparo do odontólogo na relação interpessoal com o seu paciente e familiares em domicílio, em que o profissional tem que se adaptar ao meio, ou seja, atuar clinicamente "fora" do seu ambiente de trabalho, por meio da utilização de equipamentos portáteis e, muitas vezes, com falta de ergonomia. $2,9,11,33$

\section{CONCLUSÕES}

O cirurgião-dentista ao se deparar com casos de pacientesidososquenecessitam de atendimento domiciliar deve estar preparado e qualificado para o atendimento. Existe a necessidade de realizar estudos e pesquisas relacionadas com as principais enfermidades presentes nos idosos, para que o plano de tratamento seja executado de maneira individualizada e multidisciplinar. 
Surge a necessidade de implementar disciplinas na graduação e cursos de capacitação na área de Odontogeriatria com enfoque de assistência domiciliar, com base em um

\section{REFERÊNCIAS}

1. Araújo SSC, Freire DBL, Padilha DMP, Baldisserotto J. Suporte social, promoção da saúde e saúde bucal na população idosa do Brasil. Interface 2006;10(19):203-16.

2. Floriani CA, Schramm FR. Atendimento domiciliar ao idoso: problema ou solução? Cad Saúde Pública 2004;20(4):986-94.

3. Silveira Neto N, Luft LR, Trentin MS, Silva SO. Condições de saúde bucal do idoso: revisão de literatura. RBCEH 2007;4(1):48-56.

4. Brasil. Estatuto do idoso. Brasília: Ministério da Saúde; 2005.

5. Brasil. Constituição da República Federativa do Brasil. Brasília: Senado Federal; 2010.

6. Silva L, Galera SAF, Moreno V. Encontrando-se em casa: uma proposta de atendimento domiciliar para famílias de idosos dependentes. Acta Paul Enferm 2007;20(4):397-403.

7. Barros GB, Cruz JPP, Santos AM, Rodrigues AAAO, Bastos KF. Saúde bucal a usuários com necessidades especiais: visita domiciliar como estratégia no cuidado à saúde. Rev Saúde Com 2006;2(1):127-34.

8. Braga EC, Sinatra LS, Carvalho DR, Cruvinel VR, Miranda AF, Montenegro FLB. Intervenção odontológica domiciliar em paciente idoso cego institucionalizado: relato de caso. Rev Paul Odontol 2011;33(2):17-22.

9. Souza IR, Caldas CP. Atendimento domiciliário gerontológico: contribuições para o cuidado do idoso na comunidade. Rev Bras Prom Saúde 2008;21(1):61-8.

10. Oliveira AG, Reis SMAS, Paula AR, Carvalho TA. A integração da odontologia no programa de assistência domiciliar (PAD): uma retrospectiva. Em extensão 2010;9(1):154-62.

11. Marques GB, Freitas IBA. Experiência-piloto de assistência domiciliar: idosos acamados de uma unidade básica de saúde. Rev Esc Enfer USP 2009;43(4):825-32.

12. Miranda AF, Montenegro FLB. O cirurgião-dentista como parte integrante da equipe multidisciplinar direcionada à população idosa dependente no ambiente domiciliar. Rev Paul Odontol 2009;31(3):15-9. planejamento gerontológico em saúde, para que as ações em saúde bucal possam ser devidamente direcionadas ao público idoso que necessita desse tipo de serviço especializado.

13. Ministério da Saúde (Brasil). Envelhecimento e Saúde da Pessoa Idosa. Série A. Normas e Manuais Técnicos. Caderno de Atenção Básica; 2007. 192 p.

14. Karsch UM. Idosos dependentes: famílias e cuidadores. Cad Saúde Pública 2003;19(3):861-6.

15. Almeida GCM, Ferreira MAF. Saúde bucal no contexto do Programa Saúde da Família: práticas de prevenção orientadas ao indivíduo e ao coletivo. Cad Saúde Pública 2008;24(9):2131-40.

16. Silveira TM, Caldas CP, Carneiro TF. Cuidando de idosos altamente dependentes na comunidade: um estudo sobre cuidadores familiares principais. Cad Saúde Pública 2006;22(8):1629-38.

17. Mesas AE, Trelha CS, Azevedo MJ. Saúde bucal de idosos restritos ao domicílio: estudo descritivo de uma demanda interdisciplinar. Physis 2008;18(1):61-75.

18. Sinatra LS, Braga EC, Silva MO, Miranda AF, Montenegro FLB. A odontogeriatria contribuindo nos aspectos biopsicossociais do idoso: relato de caso. Rev Portal Divulg 2011;13:21-30.

19. Miranda AF, Miranda MPAF, Lia EM, Leal SC. Doença de Alzheimer: características e orientações em odontologia. RGO 2010;58(1):1-9.

20. Santos TS, Acevedo CR, Melo MCR, Dourado E. Abordagem atual sobre hipertensão arterial sistêmica no atendimento odontológico: [revisão]. Odontol Clín Cient 2009;8(2):105-9.

21. Rosa L, Zuccolotto MC, Bataglion C, Coronatto E. Odontogeriatria - a saúde bucal na terceira idade. RFO 2008;13(2):82-6.

22. Almeida RF, Pinho MM, Lima C, Faria I, Santos P, Bordalo C. Associação entre doença periodontal e patologias sistêmicas. Rev Port Clin Geral 2006;22:379-90

23. Doro GM, Fialho LM, Losekann M, Pfeiff DN. Projeto "Odontologia Hospitalar". Rev ABENO 2001;6(1):49-53.

24. Cavezzi Junior O, Zanatto ARL. Endocardite infecciosa: odontologia baseada em evidências. Odontol Clín-Cient 2003;2(2):85-94. 
25. Branco FP, Volpato MC, Andrade ED. Profilaxia da endocardite bacteriana na clínica odontológica - o que mudou nos últimos anos? Rev Periodontia 2007;17(3):23-9.

26. Cavezzi Junior O. Endocardite infecciosa e profilaxia antibiótica: um assunto que permanece controverso para a Odontologia. Rev Sul-Bras Odontol 2010;7(3):372-6.

27. Aerts D, Abegg C, Cesa K. O papel do cirurgiãodentista no Sistema Único de Saúde. Ciênc Saúde Coletiva 2004;9(1):131-8

28. Sousa RR, Castro RD, Monteiro CH, Silva SC, Nunes AB. O paciente odontológico portador de diabetes mellitus: uma revisão de literatura. Pesq Bras Odontoped Clin Integr 2003;3(2):71-7.

29. Padilha DMP, Castilhos ED, Mello ALSF. Abordagem sistemática para o atendimento odontológico em instituições geriátricas. Rev Fac Odonto Porto Alegre 2001;42(1):34-7.

30. Barbosa ACAS, Araújo TCCF. Pré-consulta e consulta na prática assistencial hospitalar. Mudanças 2006;14(2):205-14.
31. Brondani MA. Educação preventiva em odontogeriatria: mais do que uma necessidade, uma realidade. Rev Odonto Ciênc 2002;17(35):57-61.

32. Reis SCGB, Marcelo VC. Saúde bucal na velhice: percepção dos idosos, Goiânia, 2005. Ciênc Saúde Coletiva 2006;11(1):191-9.

33. Shinkai RSA, Del Bel Cury AA. O Papel da Odontologia na equipe interdisciplinar: contribuindo para a atenção integral ao idoso. Cad Saúde Pública 2000;16(4):1099-109.

34. Arcuri PM, Ramos NB, Scabar LF. Pacientes geriátricos do Brasil. Rev Inst. Ciênc Saúde 2006;24(1):43-5.

35. Tedeschi-Oliveira SV, Melani RFH. Atendimento odontológico domiciliar: considerações éticas. Rev Uningá 2007;14:117-28.

36. Hiramatsu DA, Tomita NE, Franco LJ. Perda dentária e a imagem do cirurgião-dentista entre um grupo de idosos. Ciênc Saúde Coletiva 2007;12(4):1051-6. 